\title{
Polymorphonuclear Leukocyte Transmigration Promotes Invasion of Colonic Epithelial Monolayer by Shigella flexneri
}

\author{
Juana J. Perdomo, * * Pierre Gounon, * and Philippe J. Sansonetti \\ *Station Centrale de Microscopie Electronique, ${ }^{\ddagger}$ Unité de Pathogénie Microbienne Moléculaire, Unité 199, Institut Nationale de la Santé \\ et de la Recherche Médicale, Institut Pasteur, 75724 Paris Cedex 15, France
}

\begin{abstract}
In vivo and in vitro, Shigella flexneri, an invasive pathogen of the human colon, cannot invade epithelial cells through their apical pole. To identify ways by which it may reach the cellular basolateral domain in order to invade, we have established an assay using the human colonic T-84 cell line grown on permeable filters. Human PMN were added to the basal pole of the cells, and invasive shigellae to their apical pole. Apical addition of bacteria induced strong transmigration of PMN, reaching a maximum after $1 \mathrm{~h}$ of incubation. Transmigration depended on a receptor-specific interaction since it was inhibited by an antiCD18 monoclonal antibody that antagonizes binding of MAC 1 on its putative epithelial cell receptor. After $1 \mathrm{~h}$ of PMN transmigration, shigellae started to invade the monolayer in areas of intense PMN infiltration. Invasion was clearly dependant on PMN transmigration since it was also inhibited by addition of an anti-CD18 monoclonal antibody. This in vitro assay is consistent with in vivo observations showing early PMN efflux within colonic crypts in the course of shigellosis. PMN transmigration may therefore allow invasion in the colon by opening the paracellular pathway to invasive microorganisms. (J. Clin. Invest. 1994. 93:633-643.) Key words: polymorphonuclear leukocytes • colonic diseases • epithelium • Shigella infections
\end{abstract}

\section{Introduction}

Shigellosis, or bacillary dysentery, is a disease of considerable public health importance, particularly in tropical areas of the developing world, where it causes a high rate of mortality among young children (1-3). Shigella flexneri, a Gram-negative bacillus belonging to the family enterobactericeae, is the major aetiological agent of the endemic form of the disease in these regions. Infection is usually confined to the epithelial layer of the colonic mucosa where it causes abscesses and ulcerations, leading to severe tissue damage that accounts for the clinical manifestations of dysentery (4).

It is generally considered that the key step in the pathogenesis of shigellosis is invasion of colonic epithelial cells by the pathogen (5). This is supported by experiments showing that $S$. flexneri has the capacity to invade mammalian cells in in vitro assays (6). In HeLa cells, bacteria enter via bacterium-

Address correspondence to Dr. Philippe J. Sansonetti, Unite de Pathogenie Microbienne Moleculaire, U 199, INSERM, Institut Pasteur, 28 Rue du Dr. Roux, F-75724 Paris cedex 15, France.

Received for publication 21 April 1993 and in revised form 13 September 1993

J. Clin. Invest.

(c) The American Society for Clinical Investigation, Inc.

$0021-9738 / 94 / 02 / 0833 / 11 \quad \$ 2.00$

Volume 93, February 1994, 633-643 directed phagocytosis (7), then lyse the membrane-bound phagocytic vacuole ( 8$)$, grow within the cytoplasmic compartment, and spread from cell to cell by using the host cell cytoskeleton as a motor $(9,10)$. According to this scheme, the first event of the infectious process is enterocyte invasion, and the inflammatory reaction that causes tissue destruction in vivo is primarily a consequence of enterocyte destruction by intracellular bacteria.

However, in a recent study, we have shown in vitro that $S$. flexneri was unable to enter the apical side of polarized intestinal epithelial Caco-2 cells grown on permeable filters ( 11 ). In vivo, infections carried out in ligated rabbit ileal loops do not show evidence of apical invasion of the epithelium (Perdomo, J., and P. J. Sansonetti, unpublished results), unlike Salmonella typhimurium infection, in which in vitro and in vivo studies have clearly demonstrated apical entry of the pathogen after local destruction of the brush border (12).

Therefore, to invade colonocytes, $S$. flexneri has to reach the basolateral side of cells. This is strongly supported by transmission electron microscopy (TEM) ${ }^{1}$ performed on colonic and rectal biopsy samples taken at the acute phase of shigellosis in humans and monkeys. In these cases, bacteria are often found in the paracellular space (13). The capacity of invasive bacteria to reach the basolateral side of the cells therefore appears to be a critical step that has not yet been elucidated.

Based on infections carried out in animal models such as rabbit ligated ileal loops ( 14; Perdomo, J., and P. J. Sansonetti, manuscript in preparation) and in monkeys (15), there is growing evidence that $M$ cells located over mucosal lymphoid follicles are a major entry site at early stages of infection. However, a major characteristic of shigellosis is the strong and extensive inflammatory reaction and tissue destruction that, at later stages, extends far beyond Peyer's patches in the rabbit ligated ileal loop model, and the lymphoid solitary nodules in monkeys and humans. At these stages, bacteria are found within the epithelial cells, suggesting that they multiply and spread from cell to cell, and that other invasion sites exist.

At the ultrastructural level, these infected areas show histopathological evidence of acute infectious colitis characterized by an expansion of the lamina propia, which becomes edematous and densely infiltrated by neutrophil polymorphonuclear (PMN) and mononuclear cells, by the presence of cryptitis and crypt abscesses, as well as subsurface hemorrhages in some areas, and by mucin depletion. These lesions are very similar to processes of colonic inflammation observed during inflammatory bowel diseases such as ulcerative colitis, in which PMN characteristically migrate across the epithelium to collect primarily in the crypts, an histopathological feature used to evaluate the level of activity of such diseases.

1. Abbreviations used in this paper: HRP, horseradish peroxidase; TEM, transmission electron microscopy. 
We therefore hypothesized that the early occurring inflammatory reaction may play a primary role at the initial stage of invasion, instead of being a secondary event to primary infection and destruction of colonocytes by shigellae. More specifically, we tested the possibility that migration of PMN through the epithelium, in response to the presence of invasive shigellae on the apical side of colonocytes, may disrupt intercellular junctions and open the paracellular pathway for bacteria to reach and infect the basolateral side of these epithelial cells in the intestinal crypts.

We tested this hypothesis in vitro using the T-84 cell line, derived by Murakami and Masui (15a) from a lung metastasis of a human colonic carcinoma (16). When grown on permeable supports, these cells form short but numerous microvilli and tight junctional structures, and have the capacity to form a polarized monolayer showing structural similarity with intestinal crypt cells $(16,17)$. Confluent monolayers achieve high stable transepithelial resistance to passive ion flow, indicating proper epithelial barrier function (18). Together with the canine epithelial cell line MDCK (19), this cell line has been used to assess transepithelial movement of neutrophils in response to chemotactic gradients achieved by compounds such as the bacteria-derived $\mathrm{N}$-formylated peptides $(20)$. This event is crucial in host defense ( 21 ) and has been modeled by several authors (22-26), using different chemotactic agents to induce transmigration of neutrophils across cultured epithelial monolayers. PMN transmigration requires specific adhesive interaction with epithelial cells. Neutrophil integrins CD1 $1 \alpha / C D 18$ (LFA I) and CD11 $\beta /$ CD18 (Mac I) (27) play a major role since an anti-CD18 monoclonal antibody can neutralize this process. However, the epithelial cell receptor to these integrins has not yet been identified ( $\mathrm{J}$. Madara, personal communication).

We have therefore reconstituted an assay system mimicking the in vivo situation, using T-84 confluent monolayers grown on permeable filters. We were interested to test these two conditions in order to mimick the situation that prevails at the base of the crypts when colonic cells have not reached full maturity and at higher levels where transition occurs between the crypt and the upper part of the Lieberkühn gland. In this cell culture system, human PMN were placed on the basolateral side of the epithelial cells, and bacteria on the apical side, in a similar way to the in vivo situation. $S$. flexneri acted as a potent chemoattracting agent. Transmigration of leukocytes allowed early and efficient invasion of 3-d monolayers, whereas in the 8-d monolayer, both PMN transmigration and invasion remained low during the first $3 \mathrm{~h}$ of infection.

Data shown in this paper clearly demonstrate that $S$. flexneri is able to induce PMN to transmigrate rapidly through a confluent epithelial monolayer, suggesting that these transmigrating PMN play an active role at initial stages of epithelial invasion by opening the paracellular pathway for bacterial entry into differentiating colonocytes, which, in vivo, would be located in the crypts of the colonic epithelium.

\section{Methods}

Cell culture. T-84 cells (passages 65-90) were grown on polycarbonate filters (3.00- $\mu \mathrm{m}$ pore size, Costar inserts; Costar Corp., Cambridge, MA) in a 1:1 mix of Dulbecco-Vogt modified Eagle's medium and Ham's F- 12 medium supplemented with $10 \mathrm{mM}$ Hepes buffer, $\mathrm{pH}$ 7.3, $40 \mu \mathrm{g} / \mathrm{ml}$ penicillin, $90 \mu \mathrm{g} / \mathrm{ml}$ streptomycin, and $10 \%$ newborn calf serum. To prepare monolayers for PMN transmigration, T-84 cells ( 5 $\left.\times 10^{5} / 100 \mu \mathrm{l}\right)$ were seeded onto inverted inserts in order to permit transmigration in the physiological direction (i.e., serosal to mucosal) by facilitating access of PMN cells to the basal side of the epithelial layer. Cells were allowed to attach overnight, after which the inserts were placed upright into 24-well culture plates, thus orienting the basolateral side of the monolayer upward (see Fig. 1). Confluency and integrity of monolayers was assessed by measuring the electrical resistance using a dual-voltage Ohmmeter clamp (Millicell-ERS; Millipore Corp., Bedford, MA), which permits measurements on monolayers grown on inserts. We tested our system on cells cultured at two time periods ( 3 and $8 \mathrm{~d}$ ) since these cells develop electrical resistances that increase with time of culture. We used monolayers that developed transepithelial resistances from 600 to $1,500 \Omega / \mathrm{cm}^{2}$ for 3 -d cells and from 1,200 to $2,500 \Omega / \mathrm{cm}^{2}$ for 8 -d cells.

$P M N$ isolation. PMN were routinely isolated from anticoagulated (heparin) whole blood collected by venipuncture from healthy donors of both sexes. Briefly, heparitinized whole blood was diluted $1: 3$ with Hank's balanced salt solution, without $\mathrm{Ca}^{2+}$ and $\mathrm{Mg}^{2+}$, at $4^{\circ} \mathrm{C}$. Lymphocyte separation medium was added (Ficoll-Hypaque; Pharmacia Fine Chemicals, Piscataway, NJ) (28), and after centrifugation platelet-rich plasma was removed, followed by dextran sedimentation at $37^{\circ} \mathrm{C}$ for $30 \mathrm{~min}$. Contaminating red blood cells were then eliminated by hypotonic lysis and PMN were finally recovered as a 90-95\% pure suspension with $98 \%$ viability as tested by dye exclusion. PMN were resuspended in tissue culture medium as described above at $10^{7} / \mathrm{ml}$, and kept at $4^{\circ} \mathrm{C}$. Experiments were carried out within $1 \mathrm{~h}$ after isolation.

Measurement of PMN transmigration. The number of transmigrating PMN was quantified by measuring endogenous peroxidase activity within PMN trapped in the monolayer with a plaque-reading spectrophotometer (29). The number of PMN was calculated in relation to a standard curve established in parallel with known numbers of PMN (data not shown). Controls for PMN transmigration were performed during the same incubation periods, by adding the chemotactic peptide FMLP to the apical side of the monolayer. We titrated the concentrations of the tripeptide required since too high or too low concentrations may inhibit transmigration (21). In our experimental conditions, $10^{-6}$ $M$ proved to be the optimal concentration to induce maximal PMN transmigration. We also tested whether exposing PMN either to FMLP or to shigella strains increased endogenous peroxidase activity. Data showed no difference in activity as compared with the same number of PMN in medium during the 2-h study (data not shown).

At the end of each transmigration assay, cell monolayers were washed several times with medium, and lysis was carried out as already mentioned. Controls for endogenous peroxidase activity were also washed in medium and treated like the epithelial monolayers. Cell lysates were recovered in $100 \mu l$ and frozen until enzymatic reactions were carried out. To carry out the reaction, $10 \mu \mathrm{l}$ of each sample of cell lysates was added to a reaction mixture composed of $0.05 \mathrm{M} \mathrm{PO}_{4} \mathrm{KK}_{2}$ buffer, $5 \mathrm{mg} / \mathrm{ml} O$-phenylenediamine (lot $100 \mathrm{H} 5030$; Sigma Chemical Co., St. Louis, MO), and $2 \mu \mathrm{l} / \mathrm{ml}$ of $30 \% \mathrm{H}_{2} \mathrm{O}_{2}$. The reaction was stopped by addition of $2 \mathrm{~N} \mathrm{H}_{2} \mathrm{SO}_{4}$ containing $0.5 \% \mathrm{Na}$ sulphate, and the reading was carried out at $492 \mathrm{~nm}$.

Bacterial strain and growth conditions. S. flexneri, M90T, a serotype 5 invasive isolate $(30)$, as well as BS176, a noninvasive plasmidless derivative of M90T, were used in these experiments. Bacteria were routinely grown in tryptic soy broth (Difco Laboratories, Detroit, MI) at $37^{\circ} \mathrm{C}$. Exponential-phase cultures $(0.3 \mathrm{OD}$ at $600 \mathrm{~nm})$ were used to infect T-84 cells. Before infecting cell monolayers, bacteria were washed in saline and resuspended in the cell medium described above.

Infection of T-84 cells and PMN transmigration. 5-6 $\mathrm{h}$ before infection and/or PMN transmigration assays, cell monolayers were washed gently several times with antibiotic-free medium containing $5 \%$ newborn calf serum. Cells were infected by adding $1 \mathrm{ml}$ of bacterial suspension to the lower reservoir at a concentration of $10^{8} / \mathrm{ml}$. Once the inserts were placed inside the wells, bacteria became in contact with the apical side of the cells (Fig. 1), as would be the case in the intestine. 3-d cells were infected either with invasive M90T or BS176, its noninvasive derivative. This latter strain was used as a control in order to evaluate 
the capacity of a noninvasive microorganism to induce PMN transmigration through an epithelial monolayer, and to numerate bacteria taken up by transmigrating PMN in our assay conditions since this strain is unable to invade epithelial cells. 8-d cells were only infected by M90T. PMN were placed in the upper reservoir at a ratio of $1: 10$, as already described (21), on the basal side of the cells. Interaction was allowed to proceed during $0.5,1$, and $2 \mathrm{~h}$ for 3 -d cells, and up to $3 \mathrm{~h}$ for 8-d cells. After each time period, inserts were washed three times with medium and incubated for an extra $1 \mathrm{~h}$ with $50 \mu \mathrm{g} / \mathrm{ml}$ of gentamicin, which kills extracellular bacteria and prevents reinfection of the cells without reaching bactericidal concentrations in the intracellular compartment. In experiments in which intercellular junctions had to be opened, $100 \mu \mathrm{M}$ EGTA was added to the gentamicin solution. Inserts were then washed extensively with medium containing EGTA. To antagonize PMN transmigration, a series of experiments were carried out using a monoclonal antibody ( R-15.7, a kind gift from Dr. R. Rothleim, Boehringer Ingelheim Pharmaceuticals, Inc.) directed against CD18, the $\beta_{2}$ subunit of LFA- 1 and Mac- 1 integrins. This antibody is known to neutralize the integrin-receptor interaction between PMN and epithelial cells (24), and it was added to the upper reservoir $15 \mathrm{~min}$ before adding PMN in the wells.

Bacterial counts in the monolayer. After thorough washing of epithelial monolayers with cell medium containing EGTA, lysis was performed in PBS-Triton X-100, 0.2\%, for $5 \mathrm{~min}$. From each sample, 100 $\mu l$ of the whole lysate and of $1: 10$ and $1: 100$ dilutions were plated onto agar plates and incubated overnight at $37^{\circ} \mathrm{C}$. Colonies were then counted and the results were expressed as the percentage of invasive bacteria in the monolayer in relation to the initial inoculum $\left(10^{8}\right.$ bacte$\mathrm{ria} / \mathrm{ml}$ ). Values were then calculated for an equivalent of $1 \mathrm{~cm}^{2}$ infected with the same bacterial inoculum. Intercellular bacteria were killed since both gentamicin and washing medium contained EGTA, which allowed disruption of intercellular junctions. In invaded monolayers, the respective number of infected PMN and epithelial cells was calculated by dissociating the monolayer with $100 \mu \mathrm{M}$ EGTA in trypsin during $30 \mathrm{~min}$. Once cells appeared separated, smears were obtained over poly-L-lysine-coated coverslips, fixed with $4 \%$ paraformaldehyde in PBS, and stained with Giemsa. Intracellular bacteria in either T-84 or PMN were counted by optical microscopy on sets of 100 cells in three assays.

Morphological techniques. For immunofluorescence, monolayers were fixed in pure methanol at $-20^{\circ} \mathrm{C}$ for $5 \mathrm{~min}$, rinsed with PBS, and stored at $4^{\circ} \mathrm{C}$ in the same buffer complemented with $0.01 \% \mathrm{Na}$ azide. All dilutions for immunostaining and incubation were done in Trisbuffered saline with $0.2 \%$ BSA. PMN were labeled with an FITC-conjugated antibody directed against the human $\mathrm{CD}-15$ molecule (clone DU-HL60-3; Sigma Chemical Co.). Bacteria were labeled with an affinity-purified rabbit serum directed against the $S$. flexneri serotype 5 somatic antigen and a tetramethylrhodamine-isothiocyanate (TRITC)labeled goat anti-rabbit IgG serum (Biosys, Compiègne, France). The bisbenzimide fluorescent dye (Hoescht 33258; Calbiochem-Novabiochem. Corp., La Jolla, CA), specific for DNA, was used to dye nuclei of T-84 monolayers as an additional test of confluency. Samples were rinsed, mounted in Moviol 4.88 (Calbiochem-Novabiochem Corp.), and examined with a confocal laser scanning microscope (Leica Inc., Deerfield, IL).

For ultrastructural observations, monolayers were fixed with $2.5 \%$ glutaraldehyde, $1.5 \%$ paraformaldehyde in $0.12 \mathrm{M}$ cacodylate buffer (complemented with $0.1 \mathrm{M}$ sucrose, $5 \mathrm{mM} \mathrm{CaCl}_{2}$, and $5 \mathrm{mM} \mathrm{MgCl}{ }_{2}$ ) for $12 \mathrm{~h}$ at $4^{\circ} \mathrm{C}$. Postfixation was carried out for $1 \mathrm{~h}$ in $1 \%$ osmium tetroxyde in the same buffer. After dehydration through a graded series of alcohols, samples were embedded in epoxy resin. Sections were stained with uranyl acetate, $1 \%$ lead citrate, and observed on a transmission electron microscope operating at $80 \mathrm{kV}$ (CM-12; Philips, Eindhoven, Holland).

Horseradish peroxidase (HRP; type 2; $4000 \mathrm{~mol}$ wt; Sigma Chemical Co.) was added in tissue culture medium at $0.002 \%$ on the apical side of the monolayers to assess the permeability of intercellular junctions, in the presence of the invasive strain M90T, over the 2-h period. Samples were fixed in $1 \%$ glutaraldehyde and $1 \%$ paraformaldehyde in phosphate buffer. 3,3-diaminobenzidine hydrochloride (DAB) reactions were carried out in $0.05 \mathrm{M}$ Tris- $\mathrm{HCl}$ buffer, $\mathrm{pH} 7.6$, together with $0.01 \% \mathrm{H}_{2} \mathrm{O}_{2}$ for $30 \mathrm{~min}$ in the dark. Postfixation, dehydration and embeding were carried out as described above. Ultrathin sections were stained with $1 \%$ lead citrate only.

\section{Results}

S. flexneri-induced transepithelial migration of PMN. To demonstrate and quantify epithelial transmigration of human PMN through T-84 cell monolayers, we took advantage of the peroxidase activity expressed in PMN and not in T-84 cells (data not shown). Our assay measured essentially PMN trapped within the monolayer, since the number of PMN that traversed the monolayer and appeared in the lower reservoir (corresponding to the apical side of the monolayer) was too low to be detected. However, scanning and transmission electron microscopy (TEM) clearly demonstrated that PMN appeared on the apical side. In control experiments of transepithelial migration $10^{-6} \mathrm{M}$ FMLP was used as a standard chemoattractant. For the experiments of infection, shigellae were placed in the lower reservoir (Fig. 1) and transmigration of PMN was allowed to proceed at different time points in 3- and 8-d monolayers. In addition to the difference in electrical resistance between these cells, TEM showed (see Fig. $5 a$ ), that 3-d cells were less elongated ( $\sim 19 \mu \mathrm{m})$ than 8-d cells $(\sim 26 \mu \mathrm{m})$. Some mitotic figures could be seen in 3-d cells, and nuclei were located at different levels between the apical and the basal side of the monolayer. However, microvilli appeared well developed, thus indicating proper differentiation. In contrast, in 8-d cells, all the nuclei were at the basal side and no further divisions were observed, making these cells tightly packed and elongated within the monolayer (data not shown).

At each time point, cell lysates were taken for measurement of peroxidase activity in order to quantify PMN trapped within the monolayer. 3-d monolayers showed that the number of PMN that transmigrated randomly in the absence of any chemoattractant was $1.40 \pm 0.03 \times 10^{4} / \mathrm{cm}^{2}$ overall during $2 \mathrm{~h}$

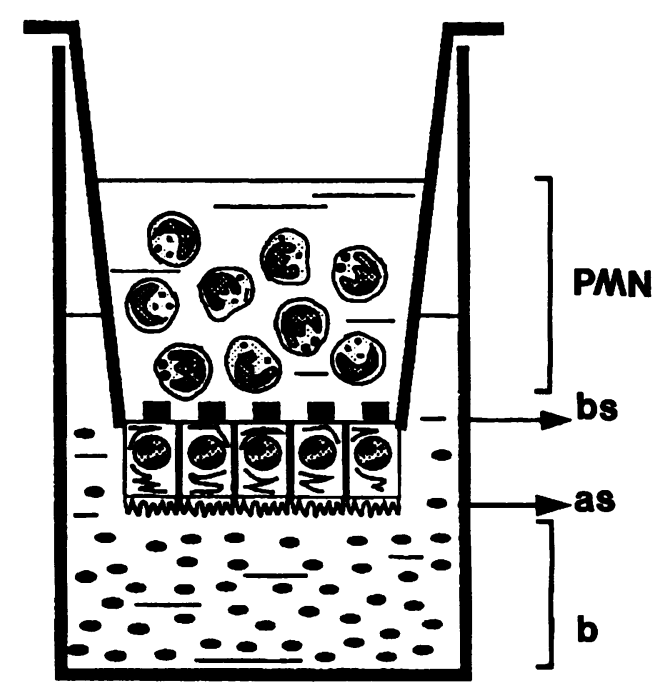

Figure 1. T-84 cells were seeded on permeable filters so that the apical surfaces of polarized confluent monolayers would be suspended in the lower reservoir, in which bacteria $(b)$ were subsequently added. PMN were placed in the upper reservoir to allow physiological direction of transmigration, from the basal side $(b s)$ to the apical side (as) of the monolayer. 


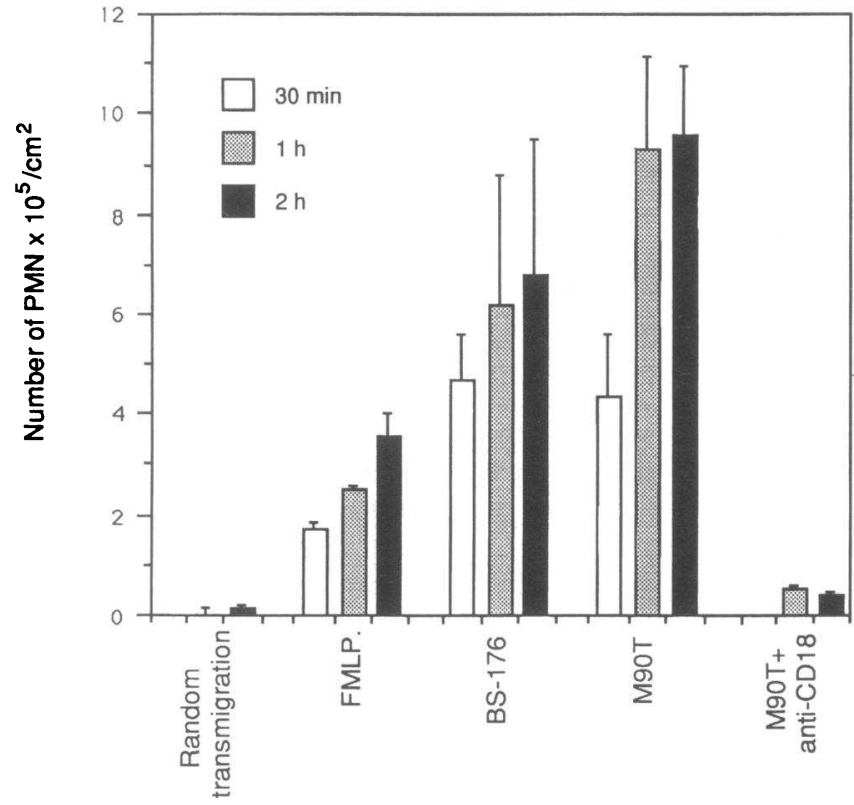

Figure 2. Number of transmigrating PMN in shigella-infected 3-d monolayers. PMN were allowed to transmigrate through T-84 confluent monolayers for $0.5,1$, or $2 \mathrm{~h}$. At each time point, peroxidase activity of cell lysates was measured to quantitate the number of transmigrated PMN. FMLP served as a positive control for PMN transmigration in response to a standard chemoattractant. Invasive $(M 90 T)$ and noninvasive (BS-176) strains were added apically to cells, and transmigration was allowed to take place. Addition of an anti-CD18 monoclonal antibody almost completely neutralized PMN transmigration.

(Fig. 2), corresponding to $0.23 \%$ of the total number of PMN added. In contrast, the addition of FMLP to the apical side of the cells induced PMN to transmigrate with much higher efficiency since the number increased from $1.70 \pm 0.16 \times 10^{5}$ $\mathrm{PMN} / \mathrm{cm}^{2}$ at $30 \mathrm{~min}$ to $3.50 \pm 0.45 \times 10^{5} \mathrm{PMN} / \mathrm{cm}^{2}$ by $2 \mathrm{~h}$ of chemoattraction, corresponding, respectively, to 2.8 and $5.8 \%$ of the total number of PMN added. These experiments validated our assay and working conditions by demonstrating that a standard chemoattractant induced significant PMN transmigration that could be quantified by the peroxidase test.
We then infected the apical side of the monolayers with the invasive M90T and noninvasive BS176 strains. Results shown in Fig. 2 represent the means and standard deviations from five experiments carried out separately. By 30 min of incubation on 3-d monolayers, both M90T and BS176 induced higher rates of transmigration than FMLP. Transmigration increased very rapidly, reaching a maximal number of intercellular PMN by $2 \mathrm{~h}$ with M90T. The maximal values induced by the invasive strain was $9.6 \pm 1.4 \times 10^{5} \mathrm{PMN} / \mathrm{cm}^{2}$ ( $16 \%$ in relation to the initial number of PMN added), and $6.8 \pm 2.7 \times 10^{5}(11.3 \%)$ for BS176. Respectively, this is three and two times the values observed with an optimal concentration of FMLP. Since the highest values of transmigrating PMN were obtained with the invasive strain, we selected this condition to test the neutralization of PMN transmigration. Addition of R.15-7, an antiCD18 monoclonal antibody that inhibits PMN adherence to epithelial cells, almost completely neutralized transmigration. The values observed fell as low as $5.30 \pm 0.07 \times 10^{4}$ and $4.20 \pm 0.05 \times 10^{4} \mathrm{PMN} / \mathrm{cm}^{2}$ after 1 and $2 \mathrm{~h}$ of incubation, respectively, which is close to the levels of random transmigration. These results confirm that adhesion of phagocytes to epithelial cells through the LFA 1 /Mac 1 integrins is necessary for transmigration, as described in previous works (9).

In 8-d monolayers, although detectable PMN transmigration occurred in the presence of the invasive strain, it did not reach the levels of 3-d cells. To see if PMN required more time to migrate through monolayers that express higher electrical resistance, we extended the time of infection and PMN transmigration to $3 \mathrm{~h}$. At $1 \mathrm{~h}$ after infection, no appreciable numbers of PMN were observed. By $2 \mathrm{~h}$, the values obtained $(0.70 \pm 0.25$ $\times 10^{4} \mathrm{PMN} / \mathrm{cm}^{2}$ ) were five times lower than those of random transmigration in 3-d monolayers, and the maximal value $4.5 \pm 1.5 \times 10^{4} \mathrm{PMN} / \mathrm{cm}^{2}$ was obtained after $3 \mathrm{~h}$ of transmigration, which is nevertheless 10 times lower than that obtained for 3-d cells after $1 \mathrm{~h}$ of incubation with either strain.

Role of PMN in invasion of epithelial cells by $S$. flexneri. To test our hypothesis that transmigration of PMN opens access of bacteria to the basolateral side of the cells, thus allowing subsequent invasion of the monolayer, intracellular bacterial counts were performed on cell lysates obtained during the course of the experiments described above in which the monolayers were infected apically. A control for maximal invasion was per-

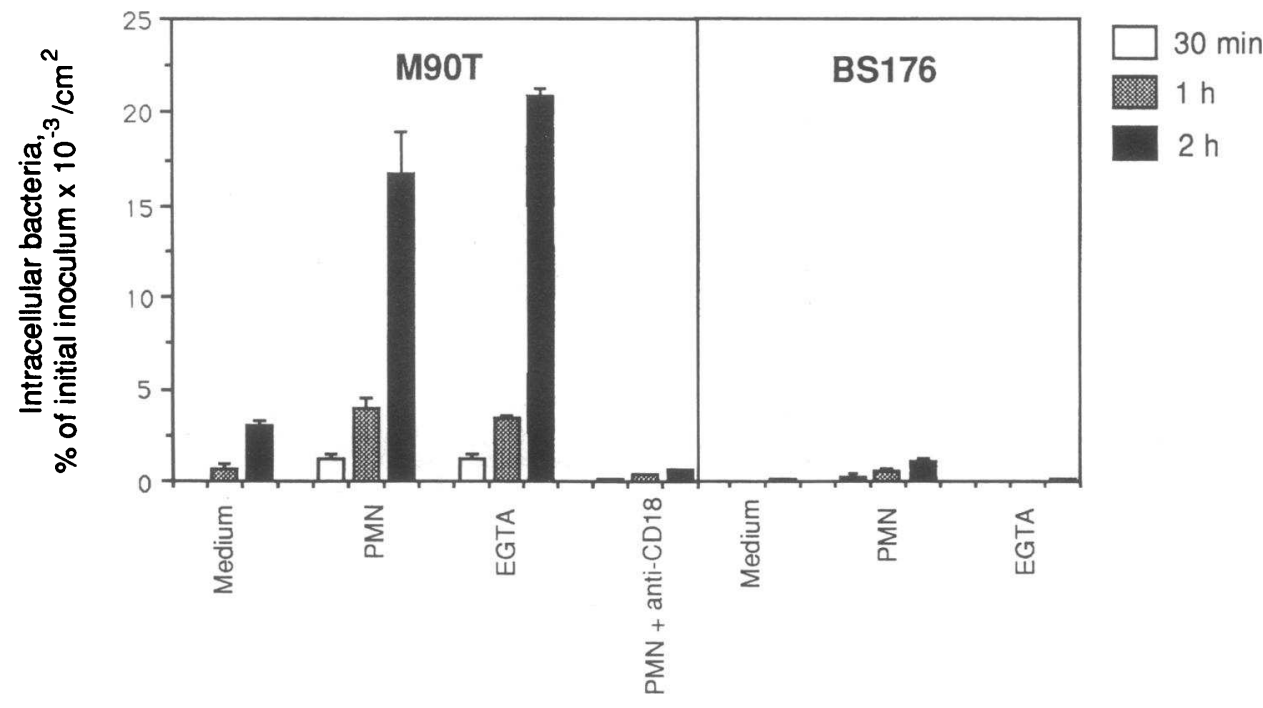

Figure 3. PMN transmigration promotes invasion of 3-d monolayers by $S$. flexneri. Cells were infected apically with the invasive and noninvasive strains of shigella, and PMN were added to the basal domain of the monolayer. Invasion was dependent on PMN transmigration since it was inhibited by addition of an anti-CD18 monoclonal antibody that impedes PMN-epithelial cell adhesion. 
formed on monolayers treated with EGTA in order to open access to the basolateral domain of cells showing a level of $0.021 \%$ after $2 \mathrm{~h}$ of incubation. In the absence of PMN (Fig. 3 ), untreated 3-d monolayers infected with invasive M90T showed an extremely low level of invasion even after the $2 \mathrm{~h}$ of incubation $(0.0029 \%)$. These values were, however, three times those obtained with 8-d cells after a 3-h incubation period $(0.001 \%)$. These observations were confirmed by immunofluoresence labeling of bacteria followed by optical sections in confocal microscopy showing a very limited number of bacteria associated with the monolayer (Fig. 4). In addition, a series of ultrathin sections were performed in order to confirm the absence of bacteria and to control the integrity of the cells. Again, no bacteria were observed either intracellular or in the paracellular space. However, by $2 \mathrm{~h}$ of incubation cells began to display abnormalities of their apical pole. Thickness of the terminal web was increased, and microvilli appeared shorter or longer depending on the cells observed. An increasing number of lysosomes were seen (Fig. $5 c$ ) as well as enlarged intercellular spaces, while intercellular junctions remained morphologically intact (Fig. 5, $b$ and $c$ ). This crucial point was confirmed by two techniques. First, the electrical resistance of the monolayer decreased to $50 \%$ of the initial resistance over the $2-\mathrm{h}$ period. In our hands, total disruption of intercellular junctions, or the presence of limited areas of monolayer destruction, causes complete breakdown of the electrical resistance. In this case the $50 \%$ decrease observed may simply be due to a transcellular effect, as previously shown with FMLP (21). Second, when HRP and bacteria were added to the apical pole of the cells, TEM showed that the molecular tracer was only associated with intracellular vesicles with no passage in the paracellular space (Fig. $5 d$ ).

In the presence of transmigrating PMN and M90T (Fig. 3), the rate of invasion of 3-d cells increased after $1 \mathrm{~h}$ of incubation, reaching values of $0.004 \%$. After $2 \mathrm{~h}$ of incubation, when bacterial invasion was six times greater than that obtained without PMN, that is, $0.017 \%$ compared with $0.0029 \%$. These values are in the same range as those obtained with EGTAtreated cells. In contrast, when transmigration of PMN was neutralized by the R.15-7 anti-CD18 monoclonal antibody, the number of bacteria infecting the monolayers decreased dramatically to $0.001 \%$ at $2 \mathrm{~h}$, a value equivalent to that observed in the absence of PMN or with the noninvasive strain BS176 in the presence of PMN by $2 \mathrm{~h}$ of incubation. These values can be considered as background invasion due to PMN uptake since BS176 did not invade EGTA-treated cells at all. In smears carried out on cells infected by M90T, we evaluated the respective distribution of intracellular bacteria in both T-84 cells and PMN, and observed that the number of infected epithelial cells was three times greater than that of infected PMN.

These results were confirmed morphologically, by double immunofluorescence and TEM. Double immunolabeling was carried out using a monoclonal antibody directed against the human PMN CD-15 receptor and a polyclonal serum directed against the $S$. flexneri 5 somatic antigen, as described in Methods. As compared with monolayers infected in the absence of PMN, which showed almost no intracellular bacteria (Fig. 4), monolayers infected in the presence of transmigrating PMN showed large numbers of intercellular and intracellular bacteria that were not only associated with PMN, but had also invaded adjacent epithelial cells with time. Optical sections obtained by confocal microscopic analysis allowed us to study three different planes, one corresponding to the apical domain (I), a second to the lateral domain (II), and a third to the basal domain (III) of the cells. At early stages of incubation (30 $\min$ ), PMN transmigrated very rapidly since they were found in the basal and lateral domain of the monolayer (Fig. 4). At this stage, very few bacteria were found within the apical or lateral domain. By $1 \mathrm{~h}$ of incubation, PMN were found in the apical domain and bacteria were seen within apical PMN, as well as in the lateral and basal domains of the monolayer. By 2 $\mathrm{h}$, an increasing number of shigellae were observed in the basal domain, where they had invaded colonocytes (Fig. 4). At this same time, PMN were still found in the apical domain, but there were very few bacteria inside, whereas the lateral domain seemed devoid of these two cell types (apart the T-84 colonocytes). In addition to resistance measurements, which showed a decrease similar to that observed with bacteria alone, the overall integrity of the monolayer during the 2-h period of the experiments was verified by staining cell nuclei with a fluorescent dye specific for DNA, thereby demonstrating that colonocytes remained confluent (data not shown).

In TEM observations of epithelial cells infected by M90T in the presence of transmigrating PMN, after $30 \mathrm{~min}$ of infection, bacteria could be seen at the level of the lateral domain of the epithelial cells, either inside PMN or free in the intercellular space (Fig. $6 a$ ). This observation confirmed that the presence of PMN had enabled shigellae to invade the monolayer. By $1 \mathrm{~h}$ of infection, many of the bacteria that had escaped phagocytosis by PMN were found between PMN and epithelial cells along the lateral domain and the basal domain of the cells (Fig. $6 b$ ). At this stage, shigellae established close contacts with the basal membrane and many were internalized. By the $2 \mathrm{~h}$ of infection, even though intercellular junctions remained intact, cells began to show an increased number of lysosomes, as well as phagolysosomes, which correspond to lysed PMN that may, at the same time, be cytotoxic to epithelial cells. A great number of shigellae were still found within epithelial phagocytic vacuoles at the base of the monolayer (Fig. 6, $c$ and $d$ ), and, as observed in confocal microscopy, these microorganisms seemed to accumulate in this area from which they invaded the monolayer and spread within the cells.

Intracellular bacteria were barely detected within 8-d monolayers infected apically with the invasive strain M90T in the absence of PMN. The maximum value reached by $3 \mathrm{~h}$ of incubation with bacteria in relation to the initial inoculum was $0.001 \%$. The percentage of invasion of 8 - $\mathrm{d}$ cells in the presence of PMN was significantly lower than that of 3-d cells. Moreover, it increased only gradually with incubation time: $0.00024,0.00053$, and $0.0016 \%$ at 1,2 , and $3 \mathrm{~h}$, respectively. Infection of these monolayers by $3 \mathrm{~h}$ of incubation was 10 -fold less than that of $3-d$ cells by the $2 \mathrm{~h}$. These data show that in the presence of PMN a striking difference exists between the capacity of 3- and 8-d cells to be infected by shigella. The morphologic observations presented in this paper correspond to 3-d cells in which PMN transmigration and associated bacterial invasion were most efficient.

\section{Discussion}

The route by which enteroinvasive pathogens such as Shigella, Salmonella, and Yersinia gain access in vivo to the intracellular compartment of intestinal epithelial cells is not yet fully understood. Answers to this crucial question should provide 

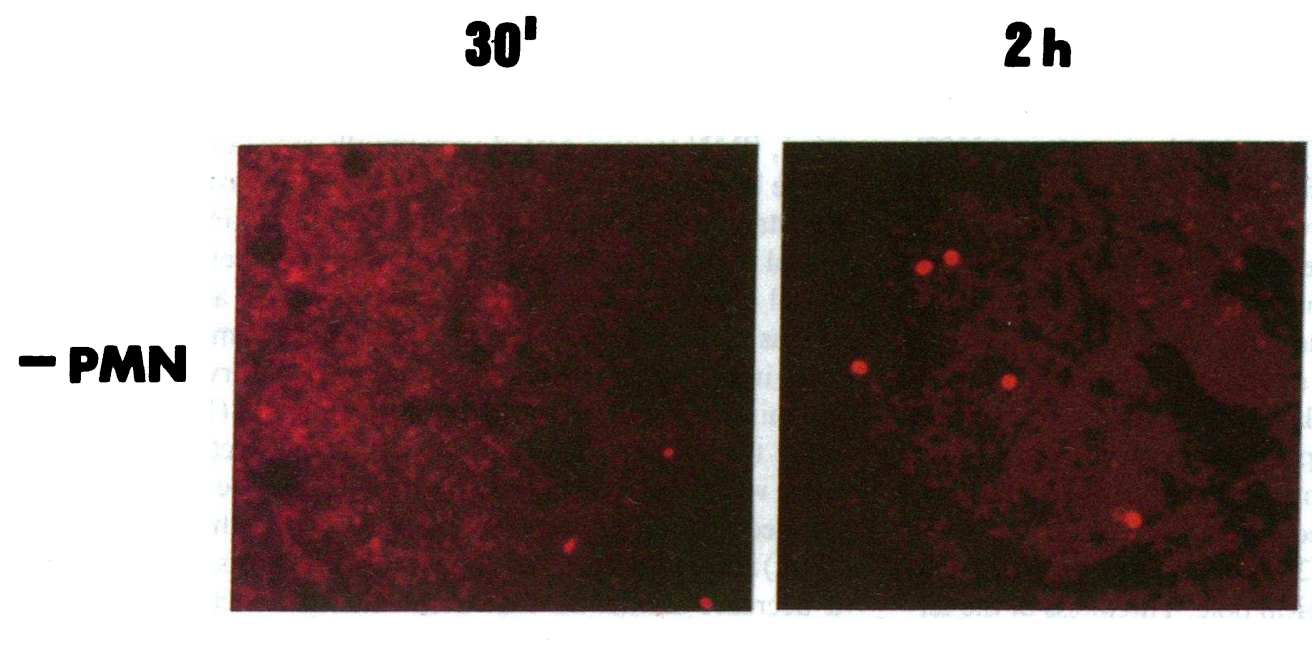

optical

section
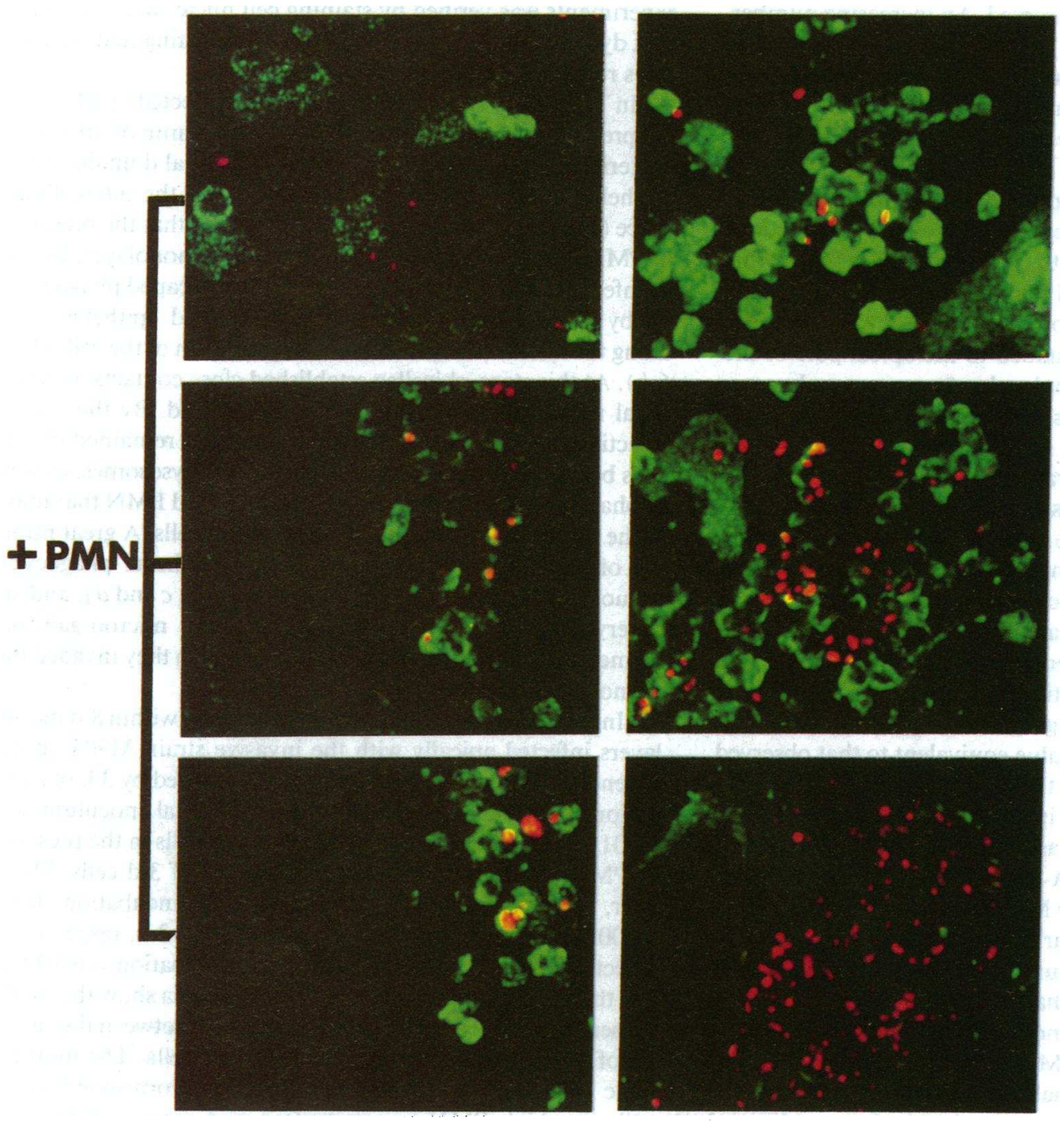

all

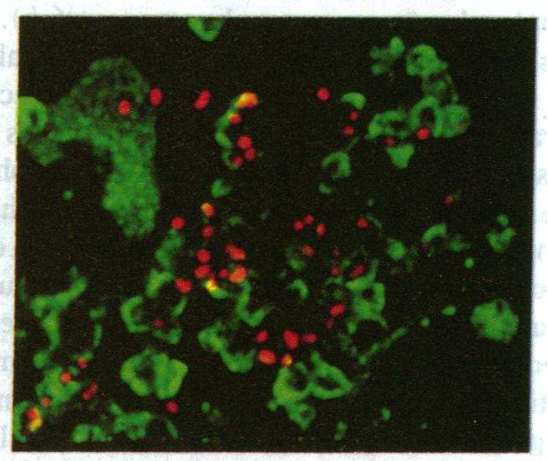

II

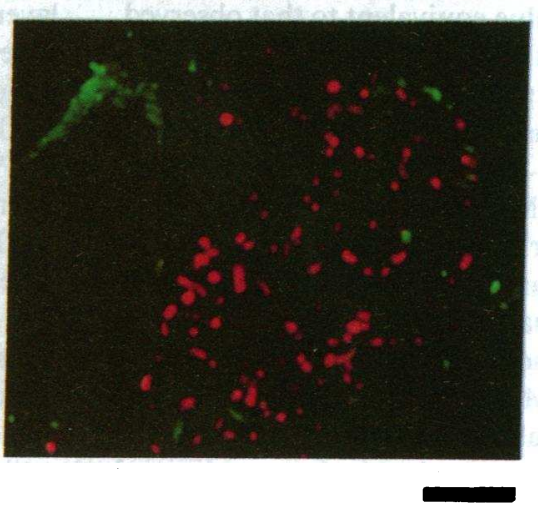

III

Figure 4. Double immunolabeling of the invasive process in 3-d monolayers. Cells were infected apically, and PMN were placed on the basal side of the monolayer. PMN were labeled with an FITC-conjugated antibody against the human CD15 molecule, and bacteria with an affinity-purified rabbit serum directed against $S$. flexneri serotype 5 somatic antigen followed by a TRITC-labeled anti-rabbit IgG serum. Optical sections of the monolayers were obtained by confocal microscopic analysis in the following way: plane $I$ corresponds to the apical domain of the monolayer, plane $I I$ to the intermediate domain, and plane $I I I$ to the basal domain. Observations were made at $30 \mathrm{~min}$ and $2 \mathrm{~h}$, both in the presence of $\operatorname{PMN}(+P M N)$ and in the absence of $\operatorname{PMN}(-P M N)$. Bar $=20 \mu \mathrm{m}$. 

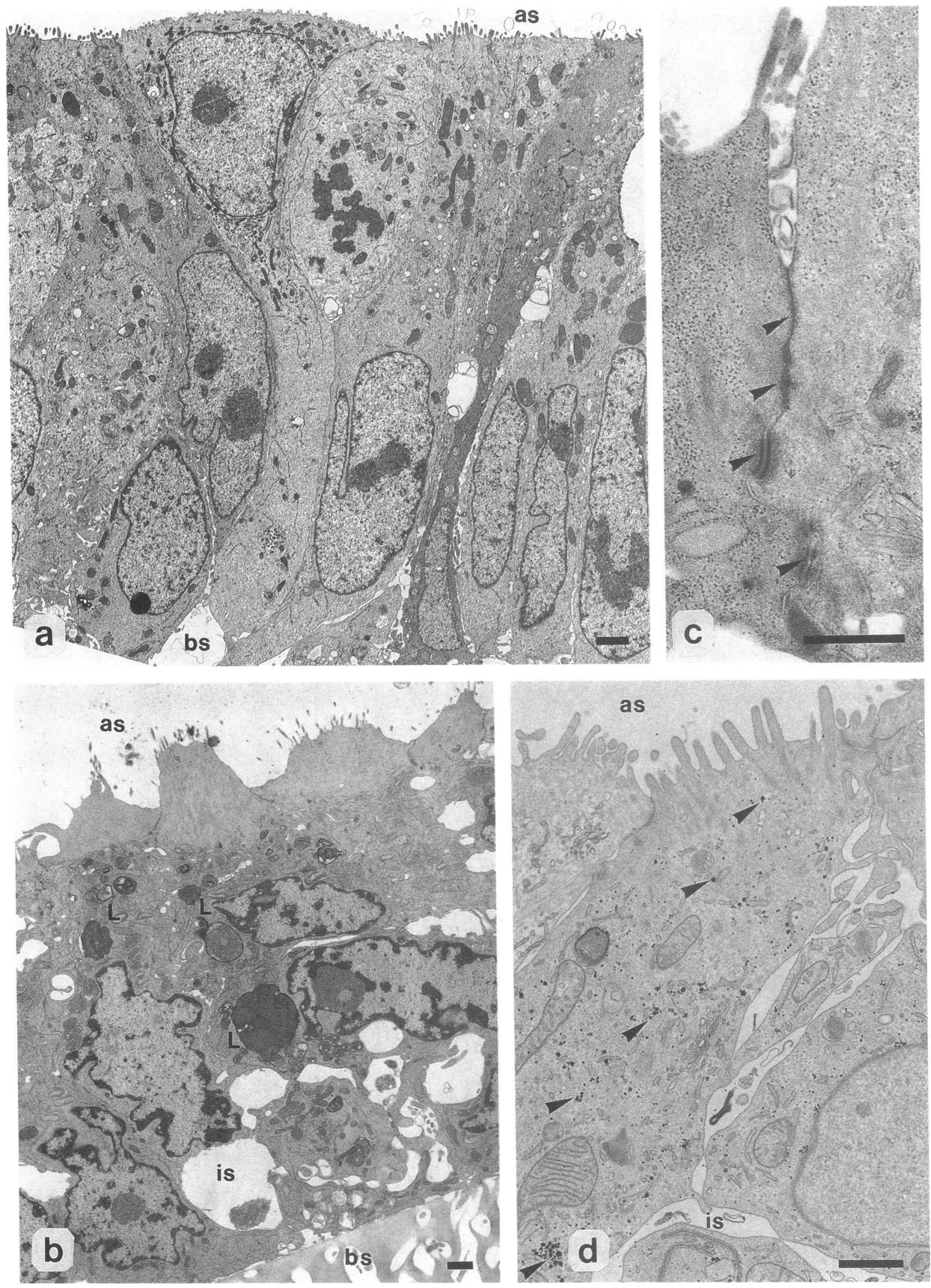

Figure 5. TEMs showing 3-d monolayers in the presence or absence of apically added invasive shigellae. $(a)$ Normal confluent monolayer showing an apical brush border, a mitotic figure, and nuclei at different levels between the apical side ( $a s)$ and the basal side $(b s)$. ( $b$ ) Monolayer infected apically with $S$. flexneri for $2 \mathrm{~h}$. We observed a great number of lysosomes $(L)$, and large intercellular spaces $(i s)$. Intercellular junctions (c) remained intact (arrowheads) as seen by the absence of the molecular tracer HRP in the intercellular spaces $(d)$. HRP was found in transcytotic vecicles (arrowheads). Bar $=1 \mu \mathrm{m}$. 

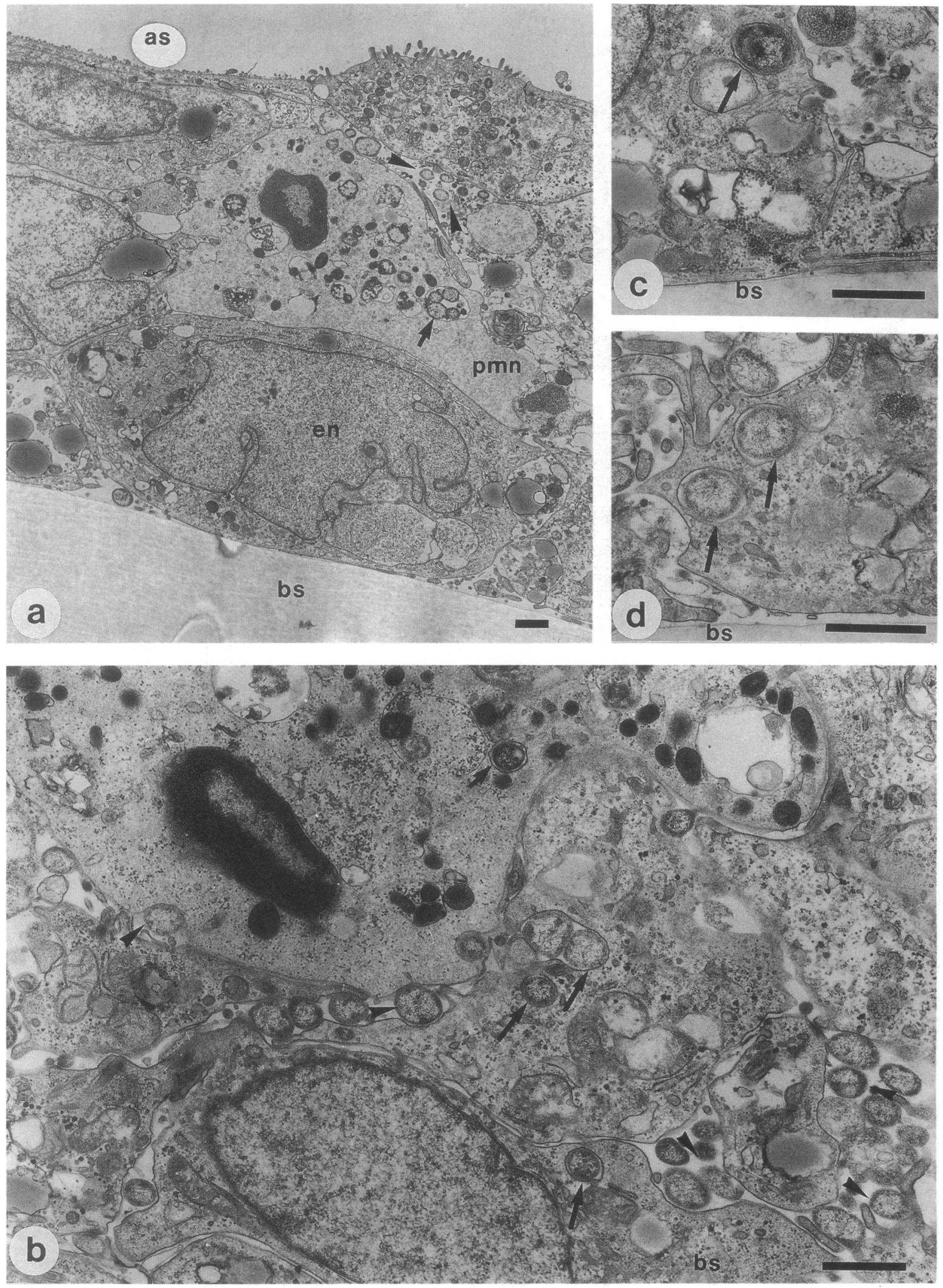

Figure 6. Invasion of colonic epithelial 3-d monolayers by S. flexneri. PMN were added to the basal side of the monolayer and bacteria to the apical side. (a) $30 \mathrm{~min}$ after infection, PMN were found in the intermediate domain of the monolayer and bacteria within phagocytic vacuoles (arrow) or in the intercellular space (arrowheads). On the apical side (as) of the monolayer, some cells hardly present any microvilli. (en) Epithelial cell nucleus. $(b) 1 \mathrm{~h}$ of infection: many bacteria were found entering the basolateral side of the epithelial cells (arrows), others were seen in the intercellular space (arrowheads), and few within PMN (little arrow). ( $c$ and $d) 2 \mathrm{~h}$ of infection: a great number of shigellae (arrows) were still found within the epithelial phagocytic vacuoles at the basal side $(b s)$ of the monolayer. Bar $=1 \mu \mathrm{m}$. 
key information on the pathogenesis of these infections as well as orientations for the design of vaccine strategies. Evidence is accumulating, both in vitro and in vivo, that in the case of shigellosis luminal bacteria cannot enter cells of the colonic epithelial lining through the apical microvilli of the brush border. To enter, they must reach the basolateral pole of the colonocytes, an area that is not exposed to the luminal content.

The first route that may allow access of bacteria to the basolateral side of the epithelium is via $\mathbf{M}$ cells. These specialized cells are present over Peyer's patches in the small intestine and in solitary nodules, the equivalent lymphoid structure of the colon. These cells continually endocytose macromolecules as well as microorganisms from the intestinal lumen (31). In the case of Salmonella and Yersinia, M cells seem to be the privileged site of entry (32). These cells also appear important in the development of shigellosis, since shigellae have been shown in $\mathrm{M}$ cells of rabbit Peyer's patches ( 11 ; and Perdomo, J., personal observations) during the first $8 \mathrm{~h}$ of infection and in human biopsies (33). In addition, when macaque monkeys are infected intragastrically with a $S$. flexneri ics A mutant that has lost the capacity to spread from cell to cell, they do not develop dysentery, but nevertheless have small colonic and rectal lesions that correspond to the solitary lymphoid nodules (12) that lie beneath $\mathrm{M}$ cells.

An alternative route that may also allow efficient access of the bacteria to the basolateral side of the intestinal epithelium is suggested by the early occurence of an intense inflammatory process that leads to dense infiltration of the lamina propria by PMN and mononuclear cells. A large number of PMN transmigrate through the epithelium, in response to invasive shigellae, leading to the formation of multiple areas of cryptitis or crypt abscesses. This is a characteristic feature of PMN transmigration that is observed both during severe acute infectious colitis and acute episodes of inflammatory bowel diseases. PMN transmigration may be of clinical importance since it causes a decrease in the epithelial barrier functions, a known functional deficit present during these inflammatory bowel diseases (34). We therefore made the hypothesis that, in response to the presence of invasive bacteria on the luminal side of the colonic epithelium, particularly within the crypts, serosal PMN may transmigrate in response to bacterial chemoattractants, thus opening the paracellular pathway for bacterial invasion to proceed.

Models of the interaction between epithelial cells and PMN have been previously described (21). Based on such assays, and on the above hypothesis, we developed an in vitro assay in which we demonstrated that basolaterally added PMN could be induced to transmigrate through epithelial T-84 monolayers $(16,21)$ in response to apical infection by $S$. flexneri. In the absence of PMN added to the system, shigellae placed on the apical side of the monolayer did not significantly invade cells during the first 2-3 h of incubation for 3- and 8-d cells, respectively. Observations by immunofluorescence and TEM confirmed the absence of bacteria invading the monolayers during the first $2 \mathrm{~h}$ of infection in spite of showing significant alterations in cellular integrity, in particular a disorganization of the brush border with areas of microvillus collapse, the presence of a great number of lysosomes, suggesting that cells were actively responding to an external component, and enlargement of intercellular spaces. These changes may reflect the transcellular effect of a toxic bacterial component that alters the monolayer integrity during the early phase of infection and most probably explains a limited drop in electrical resistance, but that does not provoke a strong enough disruption of intercellular junctions to allow macromolecular tracers such as HRP, or bacteria, to gain access to the basolateral side of epithelial cells. We are currently attempting to characterize the toxic changes that affect apically infected cells in the absence of significant invasion.

In contrast, when PMN were added basally, in addition to apically placed bacteria, to 3-d cultured T-84 monolayers, immediate (i.e., $\leq 30 \mathrm{~min}$ ) transmigration of the phagocytes was induced, and reached a rate of $9.6 \times 10^{5} \mathrm{PMN} / \mathrm{cm}^{2}$ with M90T, 100-fold higher than that of random transmigration in the absence of bacteria. However, BS176, the noninvasive strain, also induced PMN transmigration at very early stages of infection. This rate was significantly higher with both strains than that induced by $10^{-6}$ M FMLP, a standard chemoattractant for neutrophils. Transmigration was inhibited by the addition of R-15.7, a monoclonal antibody directed against the CD18 $\beta_{2}$ subunit of the LFA 1 and Mac 1 integrins (24), indicating that this transmigration process involves a specific interaction between PMN and the basolateral surface of epithelial cells involving these two integrins. Taken together, these data indicate that both invasive M90T and noninvasive BS176 strains produce a chemotactic stimulus for PMN that may correspond to a common product such as the bacterial-secreted amino-formylated peptides found in $E$. coli (FMLP) (35). However, transmigration appears more efficient with M90T or BS176 than with the optimal concentration of FMLP used. We can therefore speculate that another factor such as the LPS or the peptidoglycan of both strains contributes to the chemotactic stimulus.

As neutrophil transmigration occurred, the apically added invasive strain immediately started to invade epithelial cells, reaching maximal invasion by $2 \mathrm{~h}$ in 3-d cells. At this time point, the average rate of invasion was eightfold higher than that observed without the addition of PMN. However, the bacterial quantification procedure does not allow evaluation of the respective rates of infection of epithelial cells or PMN. To elucidate this point, we used strain BS176, which is phagocytosed by PMN but does not invade T-84 cells. This strain gave us an idea of the background of PMN phagocytosis, which appeared very low. Only with the invasive strain did we see a significant increase of bacteria in the epithelial monolayer with time, indicating that most of the bacteria are within T-84 cells. However, M90T may invade PMN more efficiently than BS176. We therefore completed the analysis by examining Giemsa-stained smears of dissociated monolayers in the presence of PMN. Two-thirds of the cells infected by M90T corresponded to T-84 cells. The invasion process by M90T was abrogated when R-15.7 monoclonal antibody was added, thus confirming that the process of PMN transmigration per se accounted for early epithelial cell invasion, most probably by opening the paracellular pathway to invasive shigellae. In the absence of an identified epithelial cell receptor for the PMN integrins (J. Madara, personal communication ), we cannot demonstrate whether, in. addition to acting as a chemoattractant, bacteria also induce enhanced expression of this putative receptor on epithelial cells. Indeed, the presence of LPS or of inflammatory cytokines, such as $\mathrm{IL}_{1}$ and $\mathrm{TNF} \alpha$, has been shown to upregulate the expression of ICAM in endothelial cells (36). In our system, bacterial components, including formylated peptides and LPS, may similarly upregulate expression of the LFA 1 and Mac 1 
integrins, as has been suggested for several products such as C5a, FMLP, and leukotrienes ( $\left.\mathrm{LTB}_{4}\right)(37)$.

In a manner reminicent of intestinal proliferating crypt cells (38), T-84 monolayers exhibit a high electrical resistance and the ability to respond to a variety of secretagogues by secreting $\mathrm{Cl}^{-}$(39). Soon after polarized monolayers are established, this cell line resembles undifferentiated crypt cells (14, 40 ), like our 3-d cultured cells, which find themselves in the stage of proliferation and therefore facilitate the passage of PMN and subsequent infection. Once monolayers are established in their morphology, electrical parameters, and ion transport activities, T-84 monolayers resemble adult colonic crypt cells (40). They are much more elongated and tightly packed within the monolayer, corresponding to 8-d cultures, through which PMN are unable to transmigrate easily. At this stage of proliferation, the apical infection of the monolayers was minimal even in the presence of basolaterally added PMN. Our observations are consistent with previous works (41) that have demonstrated that the number of PMN able to traverse an epithelial monolayer in response to a chemoattractant is inversely correlated with the transepithelial electrical resistance (42). This happens to be the case in our infectious model. We can consider two hypothesis to explain these findings. First, the higher degree of maturation of intercellular junctions, as reflected by higher electrical resistance of the monolayer, may impair both the diffusion of bacterial chemoattractants and PMN transmigration in response to this signal. Second, in response to bacterial components, 3-d epithelial cells may be induced to express a higher level of the putative receptor for PMN than 8-d cells.

In the in vivo situation, intestinal cell differentiation begins in the crypts, where colonocytes are in the stage of division and differentiation. Then, colonocytes stop dividing, reach a more advanced stage of their differentiation, and move from the crypt towards the upper segment of the Lieberkühn gland (43). In shigellosis, abscesses are often found in colonic crypts (10) at early stages of the disease, and the degree of PMN transmigration into intestinal crypts as well as the formation of crypt abscesses are indicative of disease severity. In the context of our observations, it is worth noting that the entire process of transmigration and subsequent infection appears also to take place in proliferating monolayers.

During the first stages of transmigration and infection, both M90T and BS176 were in part found in PMN even though the serum had been decomplemented to impair opsonophagocytosis of bacteria by components such as C3b and C3bi. The conflict between PMN and the invasive strain can result in the release of oxygen radicals from PMN as well as various toxic granule components like proteolytic enzymes (elastase, metallo-proteases, and serine proteases), which could destroy the connective tissue that underlies epithelia in vivo (44) or the epithelial monolayer itself both in vitro and in vivo. Under such circumstances, in our system, as suggested in Fig. 7, intracellular invasive bacteria can be released into the extracellular medium and be killed by the antibiotic added to the medium after infection has occurred. Or, they can be released into the intercellular space, find the way to reach the basolateral side of the epithelial cells, and invade, in the case of M90T but not of BS-176. The ability of PMN to damage cells may subsequently create areas of cell lysis through which surviving bacteria could easily reach the basolateral domain of adjacent colonocytes

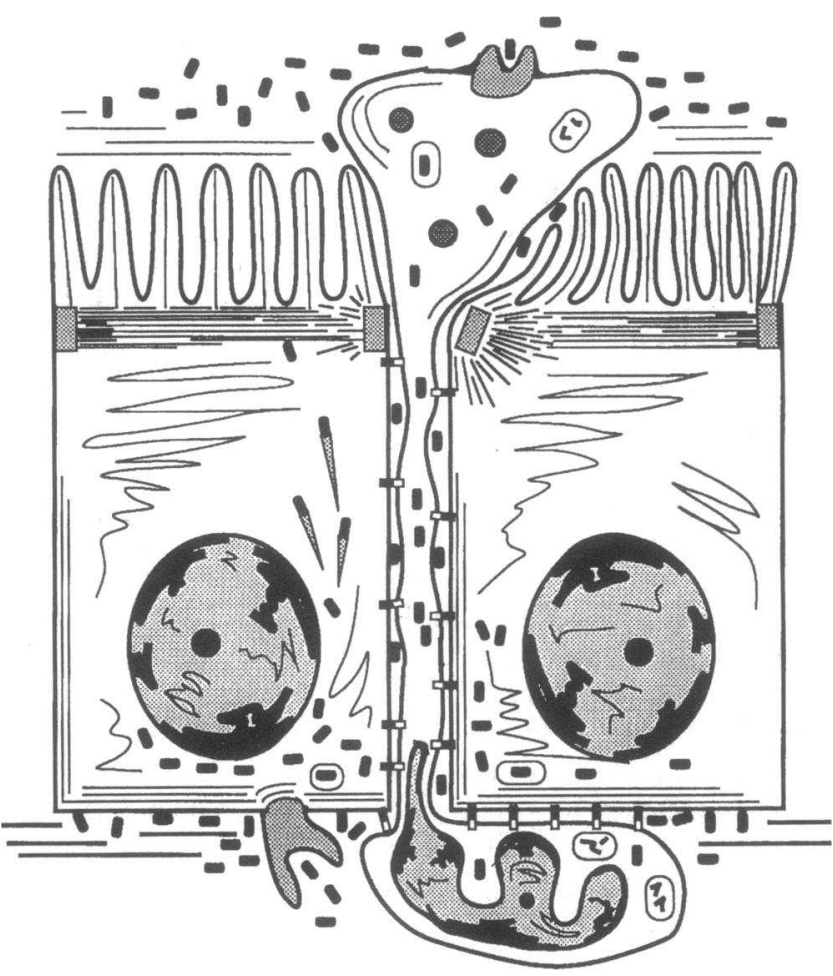

Figure 7. Proposed mechanism of early invasion of an epithelium by $S$. flexneri. The apical presence of shigellae on an epithelial monolayer provokes a chemotactic response by PMN, which are attracted from the basal side. Integrin-receptor interaction between PMN and epithelial cells permits PMN transmigration through the epithelium to the apical side. This event allows invasive bacteria to enter the epithelium by the intercellular spaces at the sites of PMN transmigration and to reach the basal side of the epithelial cells, where they subsequently invade. This scheme also mentions the possibility that some bacteria may survive in transmigrating PMN and be transported from the apical to the basal side of epithelial cells, where they can invade.

and spread from cell to cell, thus amplifying the disease process. Other studies have demonstrated a strong positive correlation between the number of transmigrating PMN and the rise in intestinal permeability (21), which may in part account for the severity of this infectious process.

In a physiological inflammatory response, neutrophils do not continuously degrade host tissues. The influx of neutrophils, along with their subsequent activation, is carefully regulated and ceases when the initiating antigen is destroyed (45). If, however, inflammatory stimuli are chronically directed against host tissues or are not properly downregulated, neutrophils can activate agents that can penetrate any of the host's defenses (44). Therefore, potential synthetic inhibitors directed against the different PMN tissue degrading components may succeed in attenuating inflammatory damage, and in this infectious process, may even decrease bacterial invasion of epithelial cells. In addition, agents that would decrease the formation of potent proinflammatory mediators such as $\mathrm{LTB}_{4}$ could perhaps diminish in part the accumulation and activation of PMN that is seen in patients with inflammatory bowel disease (23). We are currently trying to answer this critical question since enterocyte destruction during this interaction may be of direct relevance in the development of the lesions observed in vivo. 
In vitro models that reconstitute particular conditions of interaction between different cell populations in the presence of pathogens may, in the future, allow us to go beyond the scope of the interaction between a pathogen and a single cell type. Reconstitution of integrated models composed of different cell populations may permit the dissection of key steps of infectious processes in a manner that approaches more closely the complexity of the in vivo situation.

\section{Acknowledgments}

We gratefully acknowledge Dr. Robert Rothleim for providing monoclonal antibodies. We also thank Hélène Ohayon for taking part in the electron microscopy study, and Raymond Hellio for the confocal microscopy.

\section{References}

1. Mata, L. J., A. Caceres, and M. F. Torres. 1971. Epidemic shiga disentery in Central America. Lancet. i:600-601.

2. Rahaman, M. M., M. U. Khan, K. M. S. Aziz, M. S. Islam, and A. K. M. G. Kibriya. 1975. An outbreak of disentery caused by shigella dysenteriae type I on a coral island in the Bay of Bengal. J. Infect. Dis. 132:15-19.

3. Mathan, V. I., P. Bhat, C. R. Kapadia, J. Ponniah, and S. J. Baker. 1984. Epidemic dysentery caused by the Shiga bacillus in a southern Indian village. $J$. Diarrhoeal Dis. Res. 1:27-32.

4. Strulens, M. J., D. Patte, I. Kabir, A. Salam, S. K. Nath, and T. Buttler. 1985. Shigella septicemia: prevalence, presentation, risk factors and outcome. $J$. Infect. Dis. 152:784-790.

5. Labrec, E. H., H. Schneider, T. J. Magnani, and S. B. Formal. 1964. Epithelial cell penetration as an essential step in the pathogenesis of bacillary dysentery. J. Bacteriol. 88:1503-1518.

6. Sansonetti, P. J. 1991. Genetic and molecular bases of cell invasion by Shigella spp. Rev. Infect. Dis. 13(Suppl. 4):285-292.

7. Clerc, P., and P. J. Sansonetti. 1987. Entry of Shigella flexneri into HeLa cells: evidence for directed phagocytosis involving actin polymerization and myosin accumulation. Infect. Immun. 55:2681-2688.

8. Sansonetti, P. J., A. Ryter, P. Clerc, A. T. Maurelli, and J. Mounier. 1986. Multiplication of Shigella flexneri within Hela cells:lysis of the phagocytic vacuole and plasmid-mediated contact hemolysis. Infect. Immun. 51:461-469.

9. Bernardini, M. L., J. Mounier, H. d'Hauteville, M. Coquis-Rondon, and P. J. Sansonetti. 1989. Identification of icsA a plasmid locus of Shigella flexneri that goverus bacterial intra- and intercellular spread through interaction of F-actin. Proc. Natl. Acad. Sci. USA. 86:3867-3871.

10. Vasselon, T., J. Mounier, M. C. Prévost, R. Hellio, and P. J. Sansonetti. 1991. Stress fiber-based movement of Shigella flexneri within cells. Infect. Immun. 59:1723-1732.

11. Mounier, J., T. Vasselon, R. Hellio, M. Lesourd, and P. J. Sansonetti. 1992. Shigella flexneri enters human colonic Caco-2 epithelial cells through the basolateral pole. Infect. Immun. 60:237-248.

12. Wallis, T. S., W. G. Starkey, J. Stephen, S. J. Haddon, M. P. Osborne, and D. C. A. Candy. 1986. The nature and role of mucosal damage in relation to Salmonella typhimurium induced fluid secretion in rabbit ileum. J. Med. Microbiol. 22:39-49.

13. Mathan, M. M., and V. I. Mathan. 1986. Ultrastructural pathology of the rectal mucosa in shigella dysentery. Am. J. Pathol. 123:25-38.

14. Wassef, J. S., D. F. Keren, and J. L. Mailloux. 1989. Role of M cells in initial antigen uptake and in ulcer formation in the rabbit intestinal loop model of shigellosis. Infect. Immun. 57:858-863.

15. Sansonetti, P. J., Arondel J., Fontaine, A., d'Hauteville H., and L. Bernardini. 1991. ompB (osmo-regulation) and icsA (cell to cell spread) mutants of Shigella flexneri: vaccine candidates and probes to study the pathogenesis of shigellosis. Vaccine. 9:416-422.

16. McRoberts, J. A., and K. E. Barrett. 1989. Hormone-regulated ion transport in $\mathrm{T}_{84}$ colonic cells. In Functional Epithelial Cells in Culture. K. S. Matlin and J. D. Valentich, editors. Alan R. Liss., Inc., New York. 235-265.

16a.Murakami, H., and H. Masui. 1980. Hormonal control of human colon carcinoma cell growth in serum-free media. Proc. Natl. Acad. Sci. USA. 77:34643468.

17. Madara, J. L., J. Stafford, K. Dharmsathaphorn, and S. Carlson. 1987. Structural analysis of a human intestinal epithelial cell line. Gastroenterology. 92:1133-1145.

18. Hawker, P. C., J. S. McKay, and L. A. Turnberg. 1980. Electrolyte transport across colonic mucosa from patients with inflammatory bowel disease. Gastroenterology. 79:508-511.
19. Cramer, E. B., L. C. Milks, and G. K. Ojakian. 1980. Transepithelial migration of human neutrophils: an in vitro model system. Proc. Natl. Acad. Sci. USA. 77:4069-4073.

20. Chadwick, V. S., D. M. Mellor, D. B. Myers, A. C. Selden, A. Keshararzian, M. F. Broom, and C. H. Hobson. 1988. Production of peptides inducing chemotaxis and lysosomal enzyme release in human neutrophils by intestinal bacteria in vitro and in vivo. Scand. J. Gastroenterol. 23:121-128.

21. Parkos, C. A., S. P. Colgan, C. Delp, M. A. Arnaout, and J. L. Madara. 1992. Neutrophil migration across a cultured epithelial monolayer elicits a biphasic resistance response representing sequential effects on transcellular and paracellular pathways. J. Cell Biol. 117:757-764.

22. Evans, C. W., J. E. Taylor, J. D. Walker, and N. L. Simmons. 1983. Transepithelial chemotaxis of rat peritoneal exudate cells. Br. J. Exp. Pathol. 64:644-654.

23. Milles, L. C., G. P. Congers, and E. B. Cramer. 1986. The effect of neutrophil migration on epithelial permeability. J. Cell Biol. 103:2729-2738.

24. Nash, S., J. Stafford, and J. L. Madara. 1987. Effects of polymorphonuclear leukocyte transmigration on the barrier function of cultured intestinal epithelial monolayers. J. Clin. Invest. 80:1104-1113.

25. Nash, S., J. Stafford, and J. L. Madara. 1988. The selective and superoxide-independent disruption of intestinal epithelial light junctions during leucocyte transmigration. Lab. Invest. 59:531-537.

26. Casale, T. B., and M. K. Abbas. 1990. Comparison of leukotriene B4 induced neutrophil migration through different cellular barriers. Am. J. Physiol. 258:C639-C647.

27. Parkos, C. A., C. Delp, M. A. Arnaout, and J. L. Madara. 1991. Neutrophil migration across a cultured intestinal epithelium. Dependence on a CD1 lb/ CD18-mediated event and enhanced efficiency in physiological direction. $J$. Clin. Invest. 88:1605-1612.

28. English, D., and B. R. Anderson. 1974. Single step separation of red blood cells, granulocytes and mononuclear leukocytes on discontinuous density gradients of Ficoll-Hypaque. J. Immunol. Methods. 5:249-252.

29. Labrousse, H., and S. Avrameas. 1987. A method for quantification of a colored or fluorescent signal in enzyme immunoassays by photodensitometry. $J$. Immunol. Methods. 103:9-14.

30. Sansonetti, P. J., D. J. Kopeko, and S. B. Formal. 1982. Involvement of a plasmid in the invasive ability of Shigella flexneri. Infect. Immun. 35:852-860.

31. Neutra, M. R., and J. P. Kraehenbuhl. 1992. Transepithelial transport and mucosal defence I: the role of M cells. Trends Cell Biol. 134-138.

32. Grützkau, A., C. Hanski, H. Hahn, E. O. Riecken. 1990. Involvement of $M$ cells in the bacterial invasion of Peyer's patches: a common mechanism shared by Yersinia enterocolitica and other enteroinvasive bacteria. Gut. 31:1011-1015. 33. Mathan, M. M., and V. I. Mathan. 1991. Morphology of rectal mucosa of patients with shigellosis. Rev. Infect. Dis. 13:S314-S318.

34. Hawker, P. C., J. S. McKay, and L. A. Turuberg. 1980. Electrolyte transport across colonic mucosa from patients with inflammatory bowel disease. Gastroenterology. 79:508-511.

35. Schiffman E., H. V. Showell, B. A. Corcoran, P. A. Ward, E. Smith, and E. L. Becker. 1975. The isolation and partial characterization of neutrophil chemotactic factors from Escherichia coli. J. Immunol. 114:1831-1837.

36. Dustin, M. L., and T. A. Springer. 1988. Lymphocyte function associated antigen-I (LFA-I) interaction with intercellular adhesion molecule-I (ICAM-I) is one of at least three mechanisms for lymphocyte adhesion to cultured endothelial cells. J. Cell Biol. 107:321-331.

37. Gimbrone, M. A., Jr., A. F. Brock, and A. J. Schafer. 1984. Leukotriene B4 stimulates polymorphonuclear leukocyte adhesion to cultured vascular endothelial cells. J. Clin. Invest. 74:1552-1555.

38. Field, M. 1981. Secretion by the small intestine. In Physiology of the Gastrointestinal Tract. L. R. Johson, editor. Raven Press, Ltd., New York. 963983.

39. Dharmsathaphorn, K., J. A. McRoberts, K. G. Mandel, L. D. Tisdale, and H. Masuri. 1984. A human colonic tumor cell line that maintains vectorial electrolyte transport. Am. J. Physiol. 246:6204-6208.

40. Madara, J. L., and K. Dharmsathaphorn. 1985. Occluding junction structure-function relationships in a cultured epithelial monolayer. J. Cell Biol. 101:2124-2133.

41. Milks, L. C., M. Brontoli, and E. B. Cramer. 1983. Epithelial permeability and the transepithelial migration of human neutrophils. J. Cell Biol. 96:12411247.

42. Migliorisi, G., E. Folkes, and E. B. Cramer. 1988. Differences in the ability of neutrophils and monocytes to traverse epithelial occluding junctions. J. Leukocyte Biol. 44:485-492.

43. Gordon Jeffrey, I. 1989. Intestinal epithelial differentiation. New insights from chimeric and transgenic mice. J. Cell Biol. 108:1187-1194.

44. Weiss, S. J. 1989. Tissue destruction by neutrophils. N. Engl. J. Med. 320:365-376.

45. Clark, R. A. 1983. Extracellular effects of the myeloperoxidase-hydrogen peroxide-halide system. Adv. Inflammation Res. 5:107-146. 